\title{
Consumo transmídias de conteúdos televisivos: explorações em torno de uma agenda de investigação ${ }^{1}$
}

\section{Transmedia consumption in television contents: exploring possibilities on a research agenda}

\author{
Yvana Carla Fechine \\ Professora do Departamento de Comunicação Social e do Programa de Pós-graduação em Comunicação da Universidade \\ Federal de Pernambuco (UFPE). É mestre e doutora em Comunicação e Semiótica pela Pontifícia Universidade Católica de São \\ Paulo (PUCSP). \\ $<$ vvanafechine@hotmail.com>
}

\section{Karla Patriota Bronsztein}

Doutora em Sociologia e Mestre em Comunicação pela Universidade Federal de Pernambuco (UFPE). Professora do Departamento de Comunicação Social e do Programa de Pós-graduação em Comunicação da Universidade Federal de Pernambuco (UFPE).

$<$ k.patriota@gmail.com>

\section{RESUMO}

O artigo propõe uma agenda de investigação do consumo transmídia de conteúdos televisivos, fazendo uma análise exploratória de dados quantitativos referentes ao consumo dos meios capazes de dar sinalizações para a compreensão das práticas de consumo transmídias. Para a análise, usamos o software Sisem Suíte e nos debruçamos sobre o banco de dados do primeiro trimestre de 2014 do Estudo Geral dos Meios - EGM, realizado pelo Ipsos MediaCT entre dezesseis mercados brasileiros. Nesta exploração, elegemos a televisão como lugar privilegiado de observação (mídia de referência), em função dos nossos interesses de pesquisa e a partir de dados oferecidos pelo próprio EGM em relação aos chamados heavy users. A análise em pauta e as observações preliminares de campo nos permitem supor que a elaboração de conteúdos televisivos transmídias pelos produtores brasileiros deverá ser orientada muito mais por estratégias de "retroalimentação/ressonâncias" que de expansões/aprofundamentos" de conteúdos.

\section{ABSTRACT}

The paper proposes a research agenda about transmedia consumption of television content, making an exploratory analysis of quantitative data on the use of means capable of giving signals for the understanding of transmedia consumption practices. For the analysis, we use the Sisem Suite software and we worked over the first quarter of 2014 Database of Media General Study - EGM, conducted by Ipsos MediaCT between sixteen Brazilian markets. In this exploration, we have chosen television as the privileged place of observation (reference media), on the basis of our research interests and from data provided by the EGM itself in relation to so-called heavy users. Analysis on the agenda and preliminary field observations allow us to assume that the development of transmídias television content by Brazilian producers should be guided more by strategies of "feedback / resonances" that "expansions / deepening "of content.

Keywords: Transmedia consumption. Soup operas. Miniseries. 


\section{Transmidiação: Conceituação e estratégias ${ }^{1}$}

A produção contemporânea de conteúdos audiovisuais não pode mais ser dissociada da atuação dos grandes conglomerados de comunicação, que possuem interesses no cinema, na tevê aberta e a cabo, em jornais e revistas, no mercado editorial e nas mídias digitais. Esses conglomerados operam hoje de acordo com uma lógica comercial que Jenkins (2003) denomina de franquias de entretenimento referindo-se ao modo como, a partir da convergência ${ }^{2}$, um mesmo produto é explorado, sinergicamente, pelas suas diferentes empresas observando um fluxo cross-media de consumo. Neste ambiente, no entanto, as experiências de integração entre mídias assumem um caráter particular ao compatibilizarem as estratégias mercadológicas com os pressupostos da chamada cultura participativa, propiciada pela popularização dos mais variados dispositivos digitais interativos, sobretudo a partir da última década. É neste cenário que se difunde a noção de transmidiação associada às lógicas de produção e consumo de conteúdos em múltiplas plataformas ${ }^{3}$. Sem limites conceituais bem definidos, a transmidiação nos desafia a pensar sobre suas estratégias até mesmo como forma de melhor caracterizá-la como fenômeno. 0 ponto de partida para esta problematização é a ideia de transmedia storytelling forjada a partir da indústria do entretenimento.

De acordo com Jenkins, a transmedia storytelling, ou narrativa transmídia, representa um processo no qual um conjunto de elementos de uma ficção estão dispersos sistematicamente por múltiplas plataformas com o propósito de criar uma experiência unificada e coordenada de entretenimento (2003a, 2008). As narrativas transmídias envolvem a criação de universos ficcionais compartilhados pelos diferentes meios, cabendo a cada um deles desenvolver programas narrativos próprios, mas de modo articulado e complementar com os demais. As histórias que começam a ser contadas na tela do cinema têm continuidade na tela da tevê e, depois, no computador. O procedimento também ocorre ao contrário com narrativas que surgem nas telas de computador, desdobram-se

1 Adiscussão retoma ideias já desenvolvidas por Fechini em trabalhos anteriores realizados junto ao Observatório Ibero-americano da Ficção Televisiva (OBITEL Brasil) e a Red Transmediaticos, grupo latino-americano de investigadores sobre narrativa transmídia (Fechini, 2012).

2 Por convergência, entendemos aqui transformações relacionadas "[...] ao fluxo de conteúdos através de múltiplos suportes midiáticos, à cooperação entre múltiplos mercados midiáticos e ao comportamento migratório dos públicos dos meios de comunicação." (Jenkins, 2008, p.27).

3 Compreendemos aqui como plataforma a articulação de uma mídia com uma determinada tecnologia. Nesta perspectiva, é possível identificarmos distintas plataformas de distribuição de conteúdos em um mesmo meio, como ocorre, por exemplo, na tevê e na internet. 
na tela do cinema e, a partir daí, chegam à tevê. Com esse tipo de estratégia, o objetivo agora é construir um complexo mundo ficcional que sustenta múltiplas relações entre os personagens e suas histórias.

Esses desdobramentos possíveis do universo ficcional proposto se manifestam em múltiplos meios, expandindo o enredo original em distintos momentos de sua linha temporal, enfocando novos aspectos ou pontos de vista, explorando personagens secundários e/ou complexificando a atuação dos protagonistas a partir de situações e ambientes próprios a cada plataforma. Para isso, é necessário investir na proposição de universos ficcionais capazes de acolher diversos personagens, do mesmo modo que estes devem ser compostos para sustentar múltiplas situações. Na prática, os fenômenos de transmidiação mais bem-sucedidos, segundo Jenkins (2008), têm sido aqueles nos quais cada mídia dá uma contribuição ao sistema narrativo como um todo, mantendo, no entanto, sua autonomia. Idealmente, a narrativa proposta por cada meio deve fazer sentido tanto para os espectadores que tomam contato com aquele universo ficcional pela primeira vez, por meio de uma determinada mídia, quanto para os outros que buscam aquele universo ficcional em várias mídias. O desafio para criadores/realizadores passa a ser, então, compatibilizar os desdobramentos nas distintas mídias a partir do mesmo environment narrativo - um mesmo núcleo duro de personagens envolvidos em um mesmo percurso - que se expande a cada mídia.

Quando Jenkins (2008) difundiu no meio acadêmico o conceito de transmedia storytelling, o emprego de múltiplas plataformas para expressão de um mundo ficcional já não era uma novidade na indústria do entretenimento norte-americana. Desde Star Wars, que explorou sinergicamente a expansão da narrativa entre a tevê e o cinema e depois para outros meios, ainda nos anos 70, essas estratégias de integração entre mídias já vinham sendo exploradas com êxito pelos produtores hollywoodianos. No começo dos anos 90, Kinder (1991) havia, inclusive, utilizado o mesmo termo transmedia para designar fenômenos como as Tartarugas Ninja e Pokemón que exploravam um personagem ou grupo de personagens em um conjunto de produtos correlacionados, tais como filmes, seriados de tevê, quadrinhos, brinquedos, entre outros. Ela denominou esses fenômenos, na época, de "sistemas comerciais transmídias", destacando o modo como a imbricação desses produtos, criados a partir dos mesmos personagens e universos ficcionais, configurava "núcleos de entretenimento" e apelava para uma intertextualidade entre mídias inerente à cultura popular massiva (Kinder, 1991). O mérito de Jenkins (2008) foi, posteriormente, descrever e chamar a atenção para um tipo de experiência de integração entre mídias - 
operada, sobretudo pelos seriados - na qual os fãs tinham, agora, um papel fundamental na articulação dos conteúdos. Desenvolvidos em uma única mídia, os seriados tradicionais, explica Jenkins (2010, p.24), ofereciam maior orientação aos espectadores. Concebidos para múltiplas plataformas, seriados como Lost, Heroes, 24 Horas, entre outros, oferecem agora um fluxo menos linear de informação. Criam assim um espaço no qual os usuários são estimulados a buscar a conexão entre os elementos disponíveis em diferentes plataformas midiáticas, compartilhando com outros usuários aquilo que encontram em suas próprias buscas. Jenkins (2010, p.16) destaca como esse ambiente de convergência propicia, por um lado, a fluidez com que o conteúdo passa por diferentes plataformas e, por outro, a capacidade do público de empregar redes sociais para se conectar de maneiras novas, moldando ativamente a circulação desse conteúdo e desenvolvendo habilidades tanto para filtrar quanto para se envolver amplamente com os produtos espalhados nas distintas mídias. Para Jenkins $(2008 ; 2003 b)$, os consumidores são agentes criativos fundamentais na constituição do universo ficcional transmídia, pois são eles que, ao atenderem o convite para estabelecerem essas conexões, definem não apenas os usos das mídias, mas também aquilo que efetivamente circula entre elas. A emergência da cultura participativa, portanto, não é apenas a chave para caracterização dos fenômenos transmídias. É também o elemento mais importante para distinção deste novo tipo de fluxo cross-media de consumo que ficou conhecido como transmedia (transmídia).

Os modos pelos quais os consumidores são convidados a participar de experiências transmídias são também muito variados. Ainda que o próprio Jenkins (2008) não proponha nenhum tipo de categorização dentre elas, parece possível, observando os exemplos que são dados de projetos transmídias, identificarmos pelo menos duas grandes estratégias que, embora dotadas de suas especificidades, podem colaborar concomitantemente para o êxito de uma mesma experiência de integração entre mídias.

A primeira estratégia é caracterizada por uma expansão de conteúdos: ou seja, transbordamentos do universo temático proposto a partir da oferta de elementos dotados, por um lado, de uma função lúdica ou, por outro lado, de uma função narrativa propriamente dita. Neste primeiro caso, promove-se inclusive a extração de elementos do universo narrativo para o cotidiano da audiência por meio de conteúdos que estimulam o espectador a fabular, a vivenciar, a entrar em um jogo de faz de conta a partir do seu envolvimento com os personagens e as situações apresentadas. No último caso, investe-se na proposição de extensões textuais em plataformas associadas, tendo como 
referência a construção de uma transmedia storytelling, ou narrativa transmídia, tal como descrita aqui anteriormente.

Não se pode esquecer, porém, que uma narrativa transmídia é também narrativa, devendo observar, a despeito de suas especificidades, um conjunto de procedimentos que a definem como tal, já descritos em trabalhos anteriores (Fechine e Figueirôa, 2011 e Fechine, 2012). Neste caso, investe-se na complementaridade entre elementos e programas narrativos interdependentes, mas dotados de sentido em si mesmos. Há, portanto, uma organicidade entre os conteúdos postos em circulação e disponíveis para acesso dos agentes criativos (consumidores). Essa interdependência e organicidade entre os eventos distribuídos entre os diferentes meios é o que nos permite enxergar o conjunto como um tipo particular de narrativa que investe na integração entre meios para propor aprofundamentos a partir dessa distribuição articulada de conteúdos (Fechine e outros, 2013).

A articulação dos conteúdos entre as plataformas, no entanto, nem sempre é presidida pelo mesmo tipo de relação de complementaridade e aprofundamento, ainda que o objetivo seja sempre promover o engajamento do fruidor. Há casos, porém, em que os conteúdos de uma ou mais mídias estão correlacionados, mas não estão implicados diretamente uns nos outros, o que acaba configurando um segundo tipo de estratégia. A chave da experiência transmídia passa a ser, agora, a ressonância e a retroalimentação dos conteúdos. Um conteúdo repercute ou reverbera o outro, colaborando para manter o interesse, o envolvimento e a intervenção criativa do consumidor de mídias no universo proposto, mesmo que não desempenhe, a rigor, uma função narrativa. Trata-se, muito frequentemente, de uma estratégia destinada a repercutir um universo ficcional em redes sociais na web ou fora dela, acionando o gosto dos consumidores por conversarem e/ou por saberem mais sobre aquilo que consomem nas mídias. Com isso, colabora-se para manter o consumidor de mídias envolvido com o universo ficcional proposto, seja convocando-o a algum tipo de atuação colaborativa, seja simplesmente convidando-o a dar ressonância aos conteúdos propostos, agendando-os entre outros usuários ou em outras instâncias, constituindo comunidades de interesses. Observa-se ainda, sobretudo na publicidade, o desenvolvimento de conteúdos articulados em múltiplas plataformas para "reiteração" de valores. Forma-se, desse modo, um ciclo sinérgico no qual um conteúdo chama atenção sobre o outro, acionando uma produção de sentido apoiada nessas remissões recíprocas e nessa propagação por distintos meios de um determinado universo ficcional. 
Fig. 1 - Tabela 1 - Síntese das estratégias transmídias

\begin{tabular}{|c|c|}
\hline \multicolumn{2}{|c|}{ PROPAGAÇÕES } \\
TRANSMÍDIAS & EXPANSÕES TRANSMÍDIAS \\
repercussões $\bullet$ & extensões $\bullet$ desdobramentos \\
ressonâncias & complementaridades $\bullet$ \\
reiterações $\bullet$ & aprofundamentos \\
retroalimentação & \\
\hline
\end{tabular}

Considerando a diversidade de estratégias dessas ações de integração entre mídias, propomos então empregar o termo transmidiação para designar, de modo mais amplo, toda produção de sentido fundada na reiteração e familiaridade, pervasividade e distribuição em distintas plataformas tecnológicas de conteúdos associados, cuja articulação está ancorada na cultura participativa estimulada pelos meios digitais. Em outras palavras, a transmidiação pode ser pensada como uma lógica de produção multiplataforma ancorada no consumo participativo das mídias no cenário de convergência. Nesta perspectiva, não se limita apenas aos conteúdos ficcionais e de entretenimento no audiovisual, embora se observe nestes os desenvolvimentos mais expressivos até aqui. Partindo dessa conceituação de base e da identificação de estratégias mais gerais, é possível propor uma agenda de investigação do consumo transmídia de conteúdos televisivos, foco de nosso interesse, orientada por ao menos três eixos: (1) problematização teórico-conceitual dos termos em que pode se dar a apropriação das estratégias transmídias em distintos campos de produção entretenimento, publicidade, jornalismo etc. - atentando, de um lado, para as limitações e potencialidades delineadas por seus processos comunicacionais específicos e, de outro, para as propriedades técnico-expressivas das plataformas empregadas e da mídia regente; (2) definição de protocolos metodológicos para acompanhamento da circulação e recepção de conteúdos transmídias; (3) observação do consumo dos meios por parte da população brasileira, associando-o a comportamentais e atitudes.

Estamos diante, evidentemente, de uma agenda de investigação desafiadora e de longo prazo, para a qual pretendemos, por ora, apenas apontar. Entretanto, como parte deste esforço, propomo-nos, nos limites deste artigo, a 
trabalhar sobre o eixo (3), fazendo uma análise exploratória de dados referentes ao consumo dos meios, capazes de dar sinalizações para a compreensão das práticas de consumo transmídias. Para esta análise, usamos o software Sisem ${ }^{4}$ Suíte e nos debruçamos sobre o banco de dados do primeiro trimestre de 2014 do Estudo Geral dos Meios (EGM), realizado pelo Ipsos Marplan Media CT entre dezesseis mercados brasileiros que, juntos, representam $86 \%$ de todos os investimentos publicitários no Brasil ${ }^{5}$. Nesta exploração, elegemos a televisão como lugar privilegiado de observação (mídia de referência) em função dos nossos interesses de pesquisa e a partir de dados oferecidos pelo próprio EGM em relação aos chamados heavy users. ${ }^{6}$ Como se pode observar no gráfico 1, há um claro predomínio da televisão aberta: 74\% dos entrevistados declaram ser este o meio que consomem mais intensamente, havendo entre estes um predomínio dos adultos jovens (faixas entre 20 a 34 anos, que, juntos, representam $29 \%$ de todos os consumidores heavy user do meio. Os menores grupos de consumidores heavy user são encontrados nas faixas etárias de 18 a 19 anos e 65 a 69 anos, ambos com 3\%.

4 Sistema Estudos Marplan.

5 O EGM tem periodicidade trimestral e reúne amostra das seguintes praças: Grande São Paulo, Grande Rio de Janeiro, Grande Porto Alegre, Grande Recife, Grande Belo Horizonte, Grande Salvador, Grande Curitiba, Brasília/DF, Grande Fortaleza, Grande Goiânia, Grande Florianópolis, Grande Vitória e Interior de São Paulo. Para este recorte, igualmente contamos com pesquisas nas cidades de João Pessoa, Natal, Maceió e São Luiz. A pesquisa foi realizada com amostra domiciliar ( $50 \%$ probabilística e $50 \%$ projetiva), coletada através de um questionário estruturado, preenchido pelo entrevistador, face a face com o entrevistado. As perguntas são fechadas e rápidas e, em alguns casos, permitem respostas múltiplas - o que possibilita em alguns itens, as respostas ultrapassarem o percentual de $100 \%$.

6 O usuário/consumidor com maior nível de intensidade de consumo. 
Fig. 2 - Gráfico 1 - Consumo Heavy User dos meios. Amostra do filtro: 17.885 entrevistados.

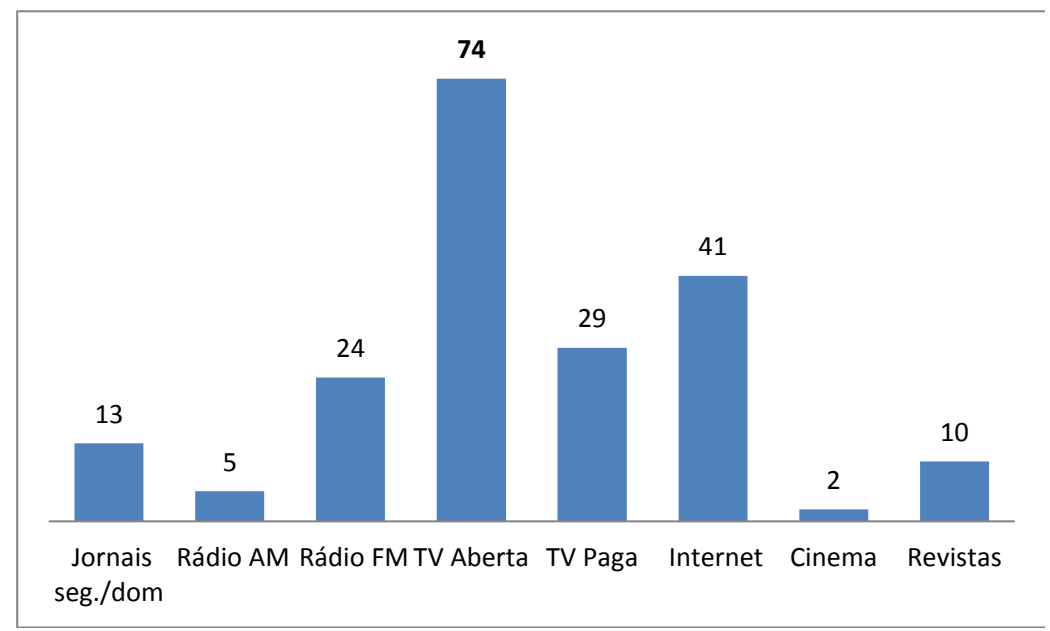

\section{Transmidiação: sinalizações a partir do consumo dos meios}

De forma mais ampla, o EGM consiste na coleta e análise dos conteúdos de mídia/consumo e comportamento/atitude dos consumidores diante dos meios de comunicação e de toda uma gama de produtos e marcas. Faz ainda um levantamento da percepção que os entrevistados possuem sobre as mídias. Para isso, perguntas que revelam se o entrevistado consome simultaneamente as mídias ou ainda se consome (e em que nível) os conteúdos de determinadas mídias em distintas plataformas foram feitos a 75.388 mil pessoas no período que analisamos (primeiro trimestre de 2014), que representam, de forma projetiva, 80 milhões de pessoas na população brasileira, das classes $A, B, C$ e D/E ${ }^{7}$ (Critério Brasil $^{8}$ ) e em todas as faixas etárias. Com base nesses dados, já é possível extrair alguns indicativos capazes de orientar a formulação de estratégias de produção e consumo transmídias a partir da televisão, mídia escolhida para esta exploração inicial.

Um primeiro dado a destacar na observação do comportamento dos entrevistados que declaram assistir à televisão diariamente são os percentuais de espectadores que ligam a tevê em busca de programas específicos (tabela 2). Trata-se de um dado que conota um maior envolvimento dos espectadores com

7 Faixa da população/ mercado com características afins em termos de grau de escolaridade do chefe de família e itens de conforto e posse familiar.

8 O critério considera a "Classificação econômica" sem a pretensão de classificar a população em termos de "Classes sociais". 
determinados conteúdos acessados, o que é uma condição sine qua non para a efetivação do consumo participativo inerente às experiências transmídias. Sem este interesse, dificilmente um espectador será levado a buscar retroalimentação ou mesmo expansões de conteúdos em outras mídias/plataformas. Outro dado a ser levado em consideração: em todas as classes econômicas é ínfimo o percentual de espectadores que consome conteúdos televisivos no celular (menos de $1 \%$ ) e/ou na internet (1\%) da população pesquisada9. Os dados mostram que não há ainda uma mudança significativa quanto ao dispositivo e situação a partir dos quais são consumidos os conteúdos televisivos.

Fig. 3 - Tabela 2 - Motivação para consumir Televisão (percentual por classe econômica)

\begin{tabular}{|c|c|c|c|c|}
\hline Motivo & A & B & C & D/E \\
\hline Passar o tempo livre & 48 & 56 & 62 & 56 \\
\hline Saber das notícias & 56 & 62 & 67 & 58 \\
\hline Sentir acompanhado & 42 & 49 & 55 & 50 \\
\hline Para se distrair & 47 & 54 & 59 & 54 \\
\hline Aprender/ cultura geral & 39 & 45 & 52 & 46 \\
\hline Informações de shows/espet./etc. & 29 & 32 & 35 & 32 \\
\hline Saber notícias de esportes & 50 & 53 & 56 & 48 \\
\hline Estar atualizado & 53 & 58 & 65 & 58 \\
\hline Ver/escutar programas especif. & 56 & 62 & 66 & 58 \\
\hline Informar sobre que deseja comprar & 33 & 39 & 46 & 42 \\
\hline
\end{tabular}

Há ainda indicadores relevantes quando investigamos o modo como as pessoas assistem à televisão. Em todas as classes, a maioria dos entrevistados conjuga o consumo do meio com atividades domésticas, sendo ainda bem poucos os que acessam outras plataformas ao mesmo tempo em que estão em frente à televisão (tabela 03). Entre os que assistem tevê diariamente e utilizam a internet há, de modo geral, o predomínio do uso da internet para acessar os sites de relacionamento, ainda que seja possível verificar, entre as classes $\mathrm{A}$ e $B$, a indicação do consumo de notícias e esportes e o hábito de baixar e assistir vídeos como principais motivos de acesso, sem que isto diminua a relevância, entre estes, da utilização das redes sociais (tabela 04).

9 Amostra do filtro: 17.885 entrevistados. 
Fig. 4 - Tabela 3 - Consumo de Televisão (últimos 30 dias) associado a outras atividades (percentual por classe econômica). Amostra do filtro: 17.515

\begin{tabular}{|l|r|r|r|r|}
\multicolumn{1}{|c}{ Assiste TV e... (simultâneamente) } & \multicolumn{1}{c}{ A } & C & D/E \\
\hline toma café da manhã & 21 & 24 & 27 & 26 \\
\hline almoça/janta & 39 & 45 & 48 & 50 \\
\hline come alguma coisa & 44 & 44 & 41 & 38 \\
\hline toma banho & 3 & 2 & 2 & 2 \\
\hline se arruma para sair & 7 & 8 & 7 & 6 \\
\hline esta no carro/meio transporte c/ pass & 1 & 1 & 0 & 0 \\
\hline responde e-mail & 7 & 5 & 2 & 1 \\
\hline fala no celular & 15 & 13 & 11 & 7 \\
\hline entra em redes sociais/blogs & 9 & 7 & 4 & 2 \\
\hline entra/posta mensagens em microblogs & 3 & 2 & 1 & 0 \\
\hline ouve rádio & 2 & 3 & 2 & 2 \\
\hline lê/folhea revista & 4 & 2 & 1 & 0 \\
\hline lê/folhea jornal & 3 & 2 & 1 & 1 \\
\hline fica navegando na internet & 12 & 9 & 5 & 2 \\
\hline lê livro & 3 & 2 & 1 & 0 \\
\hline trabalha & 4 & 4 & 3 & 3 \\
\hline faz alguma atividade doméstica & 15 & 20 & 22 & 24 \\
\hline estuda & 4 & 3 & 2 & 1 \\
\hline conversa com outra pessoa & 30 & 32 & 31 & 28 \\
\hline pratica alguma atividade física/ginástica & 3 & 2 & 1 & 1 \\
\hline nenhuma outra atividade & 17 & 15 & 16 & 16 \\
\hline outras atividades & 1 & 1 & 0 & 1 \\
\hline
\end{tabular}

Fig. 5 - Tabela 4 - Consumo de internet pelos que assistem à Televisão (últimos 30 dias) (percentual por classe econômica). Amostra do filtro: 17.515

\begin{tabular}{|l|r|r|r|r|r|}
\multicolumn{1}{c}{ Acessa Internet para... } & \multicolumn{1}{c}{ Total } & \multicolumn{1}{c}{ B } & D/E \\
\hline noticias em geral & 25 & 58 & 39 & 16 & 5 \\
\hline esporte & 10 & 25 & 15 & 6 & 2 \\
\hline baixar videos/filmes & 10 & 19 & 14 & 7 & 3 \\
\hline assistir vídeos/filmes & 9 & 17 & 12 & 8 & 3 \\
\hline acessar bate papo (chats) & 11 & 16 & 14 & 10 & 5 \\
\hline assistir TV & 2 & 3 & 2 & 1 & 1 \\
\hline fofocas/gente famosa & 4 & 7 & 6 & 3 & 1 \\
\hline sites relacionamento & 42 & 65 & 54 & 36 & 16 \\
\hline publicar/atualizar blogs & 2 & 3 & 2 & 1 & 0 \\
\hline informações exclusivas pagas & 1 & 1 & 1 & 0 & 0 \\
\hline jogar on line & 8 & 10 & 9 & 7 & 3 \\
\hline participar de forum de discussão & 1 & 3 & 2 & 1 & 0 \\
\hline
\end{tabular}


A partir destes indicadores comportamentais, surgem mais duas sinalizações significativas: o uso das redes sociais para propagações transmídias é uma aposta certeira, pois o acesso à internet em busca dos sites de relacionamento é predominante em todas as classes, embora os percentuais mais expressivos concentrem-se naquelas de maior poder econômico (tabela 4). De modo geral, porém, o uso dessas plataformas, não se dá concomitantemente à fruição da tevê, como demonstra a tabela 3, o que sugere uma maior eficácia de estratégias pautadas no consumo assíncrono das mídias e plataformas. Não estamos ainda, como se especula, sob a égide de um consumidor transmídia multitarefa.

Além da observação mais geral do comportamento de consumo de mídias, no caso da tevê, é importante atentar para as determinações dos gêneros/formatos televisuais na definição de estratégias transmídias. Entidades comunicativas por excelência da cultura de massa, os gêneros orientam todo o uso da linguagem no âmbito de um determinado meio. Podem ser pensados como matrizes de natureza estética e sociocultural que envolvem promessas de relação com o mundo (ser ficcional ou não ficcional, por exemplo) e processos de reconhecimento. Operam a partir de certos hábitos produtivos (determinados modos de produzir) e de certos hábitos receptivos (determinado sistema de expectativa do público) que precisam, portanto, ser levados em conta quando a produção de sentido aposta na articulação multiplataforma dos conteúdos.

Os dados do EGM Ipsos Marplan (tabela 5) apontam o telejornal e a telenovela/minisséries como os gêneros televisuais mais consumidos entre os brasileiros ( $80 \%$ e $69 \%$ dos entrevistados, respectivamente). Dentre estes formatos, a telenovela, é, sem dúvida, o que tem investido de modo mais assumido e inovador em estratégias transmídias. Hoje, as telenovelas da Rede Globo, principal referência e produtora do gênero no Brasil, contam com um projeto transmídia cujas ações são pensadas a partir das características da trama e ficam a cargo de uma equipe composta especialmente para este fim. As telenovelas foram o primeiro único setor de produção na Globo a contar com produtores específicos de conteúdos transmídias, embora as articulações entre tevê e internet já estivessem presentes em outros programas. As equipes transmídias são escaladas por novela e passam a, partir daí, a trabalhar diretamente com seus autores e diretores. Há, assumidamente, um interesse da Globo na transmidialização de suas telenovelas (Medeiros e 
Gontijo, 2013). Cabe então, no contexto da televisão brasileira, uma observação mais cuidadosa sobre este gênero ${ }^{10}$.

Fig. 6 - Tabela 5 - Os dez gêneros televisuais mais assistidos (percentual total e por classe econômica). Amostra do Filtro: 17.515

\begin{tabular}{|c|c|c|c|c|c|}
\hline Programas consumidos na TV & $\begin{array}{l}\text { Total } \\
\text { Geral }\end{array}$ & $\mathbf{A}$ & B & C & D/E \\
\hline TV - Noticiário geral - telejornal & 80 & 79 & 80 & 80 & 80 \\
\hline TV - Telenovelas/ minisseries & 69 & 58 & 64 & 72 & 76 \\
\hline TV - Filmes estrangeiros dublados & 62 & 73 & 66 & 60 & 52 \\
\hline TV - Transmissões esportivas - futebol & 50 & 55 & 51 & 49 & 45 \\
\hline TV - Programas de auditório & 49 & 36 & 43 & 53 & 56 \\
\hline TV - Filmes nacionais & 49 & 58 & 53 & 47 & 41 \\
\hline TV - Humorismo & 45 & 44 & 45 & 46 & 44 \\
\hline TV - Campeonatos nacionais (Brasil./Copa do Brasil & 44 & 50 & 46 & 43 & 40 \\
\hline TV - Shows variados & 39 & 44 & 39 & 38 & 36 \\
\hline TV - Seriados & 38 & 47 & 42 & 36 & 31 \\
\hline
\end{tabular}

Para esta análise exploratória dos hábitos de consumo de mídias dos espectadores de novelas e minisséries pareceu-nos pertinente observar também, neste segmento que tem predileção pela teledramaturgia, o tipo de utilização e a intensidade de consumo da internet ${ }^{11}$. Esta intensidade foi aferida a partir de três indicadores: consumo ocasional, frequente e muito frequente dos espaços online. Desprezamos o primeiro não apenas pela inexpressividade dos números quanto pela pressuposição de que o consumo ocasional não é relevante para definição de estratégias transmídias. Em todas as classes, os entrevistados declaram que o uso mais intenso da internet (categorias frequente ou muito frequente) se dá para acessar sites de busca. Entretanto, é razoável supor que o acesso aos sites de busca não representa, via de regra, uma finalidade em si mesma. Passa então a ter mais relevância a constatação que, depois do acesso aos sites de busca, o uso da internet indicado como frequente ou mais frequente pelos telespectadores de telenovelas/minisséries seja para entrar em sites de relacionamento (tabelas 6 e 7). No caso específico dos consumidores de telenovelas/minisséries que têm o hábito de acessar as

10 O OBITEL vem acompanhando esse processo desde 2009. Cf., por exemplo: Lopes, 2011, e Lopes e Gómez, 2011.

11 Para isso estabelecemos como filtro as atividades relevantes para pensar o consumo transmídia, ignorando atividades como uso para pesquisas profissionais ou compra em sites de leilão, entre outros. 
redes sociais muito frequentemente (exceto os agrupados na classe A), eles o fazem com percentuais maiores do que o acesso muito frequente aos sites de buscas (tabela 7). Estes hábitos dos espectadores de novelas e minisséries confirmam a tendência geral de consumo da internet apontada na tabela 4 e, novamente, reforçam o potencial das redes sociais digitais na construção de estratégias transmídias associadas à teledramaturgia.

No Brasil, os sites de relacionamento com o maior número de usuários são o Facebook ${ }^{12}$ e o Twitter ${ }^{13}$. Contudo, o Youtube, que também é considerado com um site de "relacionamento" em outros moldes, abarca o segundo lugar na participação dos brasileiros: 47\%, de acordo com o EGM Online (2014). Interessou-nos, então, saber se os espectadores de telenovelas utilizavam tais plataformas para o relacionamento online ${ }^{14}$. Os dados revelam uma predominância geral de menções ao Facebook (40\%), com algumas diferenças em relações às classes econômicas (tabela 8). No caso específico das novelas, a intensidade de uso das redes sociais e, dentre estas, a expressividade do Facebook - plataforma amplamente usada para discussões do cotidiano e ainda apresentando crescimento no País ${ }^{15}$ - indicam o quanto a televisão e a internet podem operar, sinergicamente, a partir de uma característica fundamental dos consumidores do gênero já apontada por estudiosos da teledramaturgia brasileira: o gosto do público por conversar sobre e a partir das telenovelas.

As conversas provocadas pelas telenovelas não dizem respeito apenas ao destino dos personagens e aos caminhos que a história tomou ou pode tomar. Tratam também de problemas sociais e dilemas morais que estão subjacentes às situações vividas pelos personagens ou às suas caracterizações. Lopes (2009)

12 De acordo com o EGM Online (2014), que considerou apenas os brasileiros que acessam a internet, o Facebook desfruta da preferência de $91 \%$ dos entrevistados.

13 Que apesar de só apresentar 1\% de menções na pesquisa do EGM - Ipsos, fechou o ano de 2014 com um crescimento de $25,6 \%$ - considerado o maior crescimento percentual visto na plataforma desde 2010 no Brasil. (Fonte: Divulgação Twitter. Disponível em: <http://www.adnews. com.br/internet/twitter-tem-maior-crescimento-no-brasil-desde-2010>. Acesso em: 24 jan. 2015.

14 Neste caso, não consideramos todas as menções a outros sites e portais que viabilizam o acesso aos diversos sites de relacionamento atualmente disponíveis, nos concentramos apenas nas plataformas que observamos como as mais usadas para as estratégias transmídia.

15 Em 2014, o Facebook completou dez anos e contabilizou 1,23 bilhões de usuários ativos, cerca de $20 \%$ da população mundial . Disponível em: $\leq$ http://www.portugues.rfi.fr/geral/20140204facebook-comemora-dez-anos-com-crescimento-e-mais-de-2-bilhoes-de-usuarios $>$. Acesso em: 24 jan. 2015. De acordo com o EGM Online, 2014, entre os brasileiros que acessam a internet, $75 \%$ o fazem para acessar as redes sociais, com prioridade para o Facebook. Muito embora, o Instagram tenha crescido em $66 \%$ sua base, em 2013, agregando 60 milhões de novos usuários ativos mensais. 
lembra que a telenovela brasileira já abordou questões polêmicas como a reforma agrária, o "coronelismo", a especulação imobiliária, as companhias multinacionais, a corrupção política, o racismo, as minorias, entre outras. Ao tratar de tais questões, a telenovela brasileira tem funcionado, segundo a autora, como uma instância de debate público, definindo "uma certa pauta que regula as interseções entre a vida pública e a vida privada" (Lopes, 2009, p.23), dando visibilidade a certos assuntos, comportamento, problemas sociais ou dilemas morais, e não a outros. Abre-se, em função dessa prática, um campo novo e fértil de exploração de elementos correlacionados aos temas propostos pela telenovela a partir de estratégias de retroalimentação de conteúdos entre as plataformas (Fechine, Figueirôa e Cirne, 2011).

Fig. 7 - Tabela 6 - Utilização (frequente) da internet por espectadores de telenovela (percentual total e por classe). Amostra do filtro: 11.932

\begin{tabular}{|l|r|r|r|r|r|}
\hline \multicolumn{1}{|c}{ Frequentemente } & \multicolumn{1}{c}{ Total } & A & B & C & D/E \\
\hline Utiliza para bate papo & 4 & 5 & 5 & 4 & 3 \\
\hline Utiliza para publicar/atualizar blogs & 1 & 2 & 1 & 1 & 0 \\
\hline Utiliza para ver/part. blogs & 1 & 2 & 1 & 0 & 0 \\
\hline Utiliza para sites relacionamento & 10 & 13 & 11 & 10 & 6 \\
\hline Utiliza para sites busca & 13 & 15 & 16 & 12 & 6 \\
\hline Utiliza para progr. lazer & 2 & 7 & 4 & 1 & 0 \\
\hline Utiliza para fofocas/gente famosa & 3 & 5 & 4 & 2 & 1 \\
\hline Utiliza para jogar on line & 4 & 4 & 4 & 4 & 2 \\
\hline Utiliza para baixar vídeos/filmes & 5 & 10 & 7 & 4 & 2 \\
\hline Utiliza para assistir videos & 4 & 9 & 6 & 4 & 2 \\
\hline Utiliza para assistir TV & 1 & 2 & 1 & 0 & 0 \\
\hline
\end{tabular}

Fig. 8 - Tabela 7 - Utilização (muito frequente) da internet por espectadores de telenovela (percentual total e por classe). Amostra do filtro: 11.932

\begin{tabular}{|l|r|r|r|r|r|}
\hline \multicolumn{1}{|c|}{ Muito frequentemente } & \multicolumn{1}{c}{ Total } & A & B & C & \multicolumn{1}{c|}{ D/E } \\
\hline Utiliza para bate papo & 5 & 9 & 7 & 5 & 2 \\
\hline Utiliza para publicar/atualizar blogs & 1 & 2 & 1 & 0 & 0 \\
\hline Utiliza para ver/part. blogs & 1 & 3 & 1 & 0 & 0 \\
\hline Utiliza para sites relacionamento & 29 & 53 & 41 & 24 & 10 \\
\hline Utiliza para sites busca & 26 & 58 & 39 & 18 & 7 \\
\hline Utiliza para progr. lazer & 1 & 4 & 2 & 1 & 0 \\
\hline Utiliza para fofocas/gente famosa & 2 & 3 & 2 & 1 & 1 \\
\hline Utiliza para jogar on line & 3 & 5 & 5 & 3 & 1 \\
\hline Utiliza para baixar vídeos/filmes & 3 & 9 & 5 & 2 & 1 \\
\hline Utiliza para assistir videos & 3 & 6 & 4 & 3 & 1 \\
\hline Utiliza para assistir TV & 1 & 1 & 1 & 1 & 0 \\
\hline
\end{tabular}


Fig. 9 - Tabela 8 - Sites/portais mencionados para acessar as redes sociais. (total e por classes). Amostra do filtro: 11.932

\begin{tabular}{|l|r|r|r|r|r|}
\hline \multicolumn{1}{|c}{ Total menções -Sites relacionamento } & \multicolumn{1}{c}{ Total } & A & B & \multicolumn{2}{c|}{ C D/E } \\
\hline Facebook & 40 & 66 & 52 & 35 & 17 \\
\hline Twitter & 1 & 3 & 1 & 1 & 0
\end{tabular}

\section{Considerações finais}

O levantamento e análise de dados do EGM Ipsos Marplan, explorados aqui como etapa inicial de uma agenda de investigação do consumo transmídia, sinaliza, ao final, um grande dilema para os produtores de conteúdos televisivos nesse cenário de convergência: a incipiente inserção do público brasileiro sobretudo, nas classes econômicas $\mathrm{CeD/E}$ - na dinâmica da cultura participativa. Para Jenkins (2006), o cerne dessa cultura participativa é a transformação do consumidor de mídias também em um produtor de conteúdos distribuídos por canais alternativos abertos pela internet (plataformas colaborativas, rede sociais, por exemplo). Estes conteúdos são o resultado, muitas vezes, da apropriação e reelaboração do que é posto em circulação pelos conglomerados de mídias (recriações, paródias) e, no extremo, culminam com a produção dos chamados fandoms, dos quais surgem práticas como downloads e distribuição de episódios oficiais, spoiling, criação de sites e episódios próprios a partir das narrativas canônicas. Para Jenkins (2006, p.136), a mais legítima expressão dessa cultura participativa está nessas comunidades de fãs que interagem com o ecossistema midiático orientado por uma inteligência coletiva (conhecimentos construídos de modo colaborativo pela rede).

Em uma chave mais geral, é possível compreender o consumo transmídia como o modo de consumir as mídias no seio dessa cultura participativa, tal como descrita por Jenkins (2008). Nesta perspectiva, porém, a problematização teórico-conceitual dos termos em que pode se dar a apropriação das estratégias transmídias em distintos campos de produção deve começar pela caracterização do modo como a cultura participativa se manifesta em cada um deles a partir, também, dos estágios e configurações econômicas, tecnológicas e socioculturais de cada país. Evidentemente, quando olhamos para a televisão brasileira, estamos diante de um cenário muito distante das práticas de produção e consumo transmídias analisados por Jenkins (2008) a partir dos seriados norte-americanos. Para estas distinções, colaboram determinações de várias ordens - a começar pelo acesso fácil e qualificado à rede -, mas, interessa-nos, 
sobretudo, olhar para características específicas de produção e consumo dos produtos culturais de maior alcance na tevê brasileira, entre eles, a telenovela ${ }^{16}$.

No contexto nacional, os indicadores com os quais trabalhamos aqui revelam uma predisposição dos que assistem à televisão diariamente para o uso das mídias sociais, indicando sua pertinência e potencial na elaboração de estratégias transmídias. No entanto, mesmo nessas plataformas, pode-se constatar no total (42\%) e por classe ainda uma participação moderada (tabela 4). Observando, de modo particular, o comportamento dos telespectadores que consomem telenovela, essa dificuldade fica ainda mais evidente. Segundo os dados do EGM Ipsos Marplan, as faixas de público que mais assistem às telenovelas são a classe D/E (72\%) e a classe C (71\%) ${ }^{17}$. Em ambas, o percentual dos que publicam/atualizam blogs - o que sugere um comportamento mais ativo na rede - é ínfimo. O percentual dos que acessam sites de relacionamentos experimenta um crescimento maior,já que observamosque $10 \%$ dosqueassistem telenovelas e minisséries frequentemente acessam sites de relacionamento e $29 \%$ acessam muito frequentemente (tabelas 6 e 7, respectivamente), contudo os números mais expressivos estão nas classes $A$ e $B$ e não no contingente maior de espectadores dos formatos em questão, a despeito de ser esta uma das práticas na internet preferidas pelos que consomem tevê.

A análise dos dados do EGM Ipsos Marplan, aliada a observações preliminares de campo, nos permite supor, por ora, que a elaboração de conteúdos televisivos transmídias pelos produtores brasileiros deverá ser orientada muito mais por estratégias de "retroalimentação/ressonâncias" que de "expansões/aprofundamentos" de conteúdos (tabela 1). As estratégias de propagações transmídias permitem explorar com eficácia essa nossa predileção por conversar, por estar em contato uns com os outros nos sites de relacionamento, o que nos parece uma constatação inicial importante dentro da complexa agenda de investigação que temos pela frente para compreender essas novas práticas.

\footnotetext{
16 Para uma discussão sobre as potencialidades e limitações para desenvolvimento de uma narrativa transmídia a partir da telenovela, veja Fechine, Figueirôa \& Cirne (2011).

17 Filtro: Ambos sexos com 10 anos e mais anos. Total do Universo (em mil): 75388, amostra do Filtro: 17885, dados referentes ao primeiro trimestre de 2014.
} 


\section{Referências}

FECHINE, Y., FIGUEIRÔA, A., CIRNE, L. Transmidiação: explorações conceituais a partir da telenovela brasileira. In: LOPES, M. I. V. (org.) Ficção televisiva transmidiática no Brasil: plataformas, convergência, comunidades virtuais. Porto Alegre: Sulina, 2011.

FECHINE, Y. Transmidiação, entre o lúdico e o narrativo. In: RENÓ, D., GOSCIOLA, V., CAMPALANS, C. (orgs.) Narrativas transmedias: entre teorías y prácticas. Bogotá: Editorial Universidad del Rosario, 2012.

FECHINE, Y e outros. Como pensar os conteúdos transmídias na teledramaturgia brasileira? Uma proposta de abordagem a partir das telenovelas da Globo. In: LOPES, M.I.V (org.) Estratégias de transmidiação na ficção televisiva brasileira. Porto Alegre: Sulina, 2013. Disponível em: < http://obitelbrasil. blogspot.com.br/>. Acesso em: 1 nov. 2014.

JENKINS, H. Os sentidos da convergência (entrevista concedida a Vinicius Navarro). Revista Contracampo. Universidade Federal Fluminense, Niterói (RJ), n. 21, 2010.

Cultura da convergência (Trad. S. Alexandria). São Paulo: Aleph, 2008.

Fans, bloggers and gamers. Exploring participatory Culture. New York: New York University Press, 2006.

- Quentin Tarantino's Star Wars? Digital Cinema, Media Convergence, and Participatory Culture. In: David T. and Jenkins, H. (eds.) Rethinking Media Change, Cambridge: MIT Press, 2003. Disponível em: < $\underline{\text { http://web.mit.edu/cms/ }}$ People/henry3/starwars.html>. Acesso em: 2 fev. 2009.

Transmedia Storytelling. In: Technology Review, 2003a. Disponível em: < http:// www.technologyreview.com/biomedicine/13052/page3/>. Acesso em: 2 fev. 2009.

KINDER, M. Playing with Power in Movies, Television and Video games. In: Muppet Babies do Teenage Mutante Ninja Turtles. Berkeley/Los Angeles: University of California Press, 1991.

LOPES, M. I. V. (org). Ficção televisiva transmidiática no Brasil: plataformas, convergência, comunidades virtuais (pp. 17-59). Porto Alegre: Sulina, 2011.

- Telenovela como recurso comunicativo. Matrizes - Revista do Programa de Pósgraduação em Ciências da Comunicação da Universidade de São Paulo (USP), São Paulo (SP), Ano 3, n. 1, 2009. Disponível em: <http://www.matrizes.usp. br> Acesso em: 14 jan. 2014. 
LOPES, M. I. V. e GÓMEZ, G. O. (org). Qualidade na ficção televisiva e participação transmidiática das audiências - Anuário OBITEL 2011. Rio de Janeiro: Editora Globo, 2011.

MEDEIROS, A. e GONTIJO, G. Transmídia por quem faz: ações na teledramaturgia da Globo (entrevista). In: LOPES, M. I. V. (org.) Estratégias de transmidiação da ficção televisiva brasileira. Porto Alegre: Sulina, 2013.

Recebido em: 13/7/2015

Aceito em: 10/9/2015

Endereço dos autores:

Yvana Carla Fechine <yvanafechine@hotmail.com>

Programa de Pós-graduação em Comunicação

Universidade Federal de Pernambuco

Av. Prof. Morais Rego, 1235 - Cidade Universitária

CEP: 50670-901

Recife, PE - Brasil

Karla Patriota Bronsztein <k.patriota@gmail.com>

Programa de Pós-graduação em Comunicação

Universidade Federal de Pernambuco

Av. Prof. Morais Rego, 1235 - Cidade Universitária

CEP: 50670-901

Recife, PE - Brasil 